\title{
Desempenho, Composição Física e Características da Carcaça de Novilhos Alimentados com Diferentes Níveis de Casca de Algodão, em Confinamento ${ }^{1}$
}

\author{
Karla Alves Magalhães ${ }^{2}$, Sebastião de Campos Valadares Filho ${ }^{3}$, Mário Fonseca Paulino ${ }^{3}$, \\ Rilene Ferreira Diniz Valadares ${ }^{4}$, Pedro Veiga Rodrigues Paulino ${ }^{5}$, Mário Luiz Chizzotti ${ }^{5}$, \\ Marlos Oliveira Porto ${ }^{6}$, Marcos Inácio Marcondes 7 , Kamila Andreatta ${ }^{7}$
}

\begin{abstract}
RESUMO - Este trabalho foi realizado com o objetivo de avaliar o efeito de níveis de casca de algodão sobre o consumo e a digestibilidade aparente total dos nutrientes, a composição física e as características de carcaça e o rendimento dos cortes comerciais de novilhos confinados. Foram utilizados 18 novilhos mestiços, com peso vivo (PV) médio inicial de 230 kg. Dois animais foram abatidos no início do experimento para servirem de referência para estudos posteriores e os demais (16) foram distribuídos em delineamento inteiramente casualizado em quatro tratamentos: 0, 10, 20 e 30\% de casca de algodão com base na MS total, em substituição à silagem de capim-elefante, sendo a relação volumoso:concentrado de 60:40. A inclusão de casca de algodão em níveis crescentes na dieta aumentou linearmente os consumos de extrato etéreo (EE), matéria seca (MS) e fibra em detergente neutro (FDN), expressos em relação ao PV. Não houve efeito dos níveis de casca de algodão sobre a composição física e as características da carcaça e o rendimento dos cortes comerciais, com exceção da EGS, que aumentou linearmente. O nível máximo de casca de algodão utilizado no experimento (30\% na MS total) proporcionou desempenho adequado a novilhos mestiços de origem leiteira em confinamento.
\end{abstract}

Palavras-chave: consumo, subproduto, Holandês

\section{Effects of Feeding Different Levels of Cottonseed Hulls on Production and Carcass Physical Composition and Traits of Feedlot Steers}

\begin{abstract}
This trial was conducted to evaluate the effects of feeding different levels of cottonseed hulls on nutrient intake, apparent total tract digestibility, carcass physical composition and traits, and percentage of commercial cuts of confined steers. Eighteen crossbred steers averaging $230 \mathrm{~kg}$ of initial body weight (BW) were used. Two animals were slaughtered at the beginning of the trial, performing the reference group while the remaining were uniformly assigned to a complete randomized design in one of four treatments (\% of total dry matter): 0, 10, 20 or 30\% of cottonseed hulls that replaced elephant grass silage. The forage:concentrate ratio was 60:40. Inclusion of cottonseed hulls in the diet linearly increased the intake of ether extract as well as the intakes of dry matter (DM) and neutral detergent fiber (NDF) expressed as a percentage of BW. Conversely, increasing dietary levels of cottonseed hulls did no change carcass physical composition and characteristics and yield of commercial cuts except for FT that increased linearly. Good production parameters were achieved with the highest level of cottonseed hulls in the diet (30\%) in the present trial.
\end{abstract}

Key Words: byproduct, Holstein, intake

\section{Introdução}

Diante da nova ordem mundial e das grandes transformações econômicas sofridas pelo país, em que as margens de retorno econômico nas atividades pecuárias se encontram cada vez mais restritas, a busca por maior eficiência produtiva se torna uma questão de sobrevivência. Os produtores de carne devem buscar formas de reduzir custos e/ou aumentar receitas, visando à obtençao de resultados econômicos satisfatórios na atividade. Na pecuária de corte, particularmente no uso do confinamento como estratégias alimentar e gerencial para a fase de engorda dos animais, a alimentação é um dos fatores que mais onera a atividade e pode, normalmente, ultrapassar $70 \%$ do custo operacional total (Valadares Filho et al., 2002).

O volumoso, na maioria das situações, é o ingrediente mais barato da ração total e, portanto, seu uso deve ser maximizado. A produção de volumosos deve ser feita preocupando-se sempre com altos índices de produtividade, associados a qualidade nutricional superior e, evidentemente, a custos reduzidos. Com a

\footnotetext{
${ }^{1}$ Parte da dissertação de Mestrado da primeira autora. Apoio: Bünge Alimentos S.A.

2 Zootecnista, MS, Estudante de Doutorado, DZO-UFV, Viçosa-MG (kmagalhaes@vicosa.ufv.br).

3 Professor do DZO, UFV, Viçosa-MG, 36571-000.

${ }^{4}$ Professora DVT-UFV, Viçosa-MG, 36571-000.

5 Zootecnista, MS, Estudante de Doutorado, DZO-UFV, Viçosa-MG

${ }^{6}$ Médico Veterinário, Estudante de Mestrado, DZO-UFV

${ }^{7}$ Zootecnista, Estudante de Mestrado, UFV, Bolsista CNPq.
} 
obtenção eficiente de volumosos e a maximização de seu uso, o produtor dependerá menos da utilização de concentrados, reconhecidamente mais caros (Valadares Filho et al., 2002).

Nesse contexto, a casca de algodão surge como um alimento volumoso alternativo na alimentação de ruminantes. Até o momento atual, não há relatos na literatura brasileira acerca da utilização desse ingrediente na dieta de bovinos. Entretanto, em razão de sua facilidade de manipulação, aceitabilidade (Rogers et al., 2002), disponibilidade (Hsu et al., 1987) e do baixo custo (Vernlund et al., 1980), a casca de algodão tem sido largamente utilizada em dietas para bovinos em terminação em outros países, constituindo, em algumas situações, a principal fonte de volumoso disponível para os animais (Hale et al., 1969; Vernlund et al., 1980).

A casca de algodão é um subproduto nutricionalmente interessante por possuir características que a diferem da maioria dos alimentos fibrosos. Compreende a camada externa da semente do algodão com algum linter aderido, que é separado durante a produção do óleo. Para cada tonelada de caroço de algodão processado, são obtidos, aproximadamente, $245 \mathrm{~kg}$ de casca (Hall \& Akinyode, 2000). De acordo com dados da CONAB (2004/2005), estima-se que a safra brasileira 2002/2003 de algodão proporcione a produção de mais de um milhão de toneladas de caroço de algodão, o que teria o potencial de gerar cerca de 2.106,9 toneladas de casca.

A casca de algodão é considerada um alimento fibroso, de baixo valor nutricional, que tem como principal componente a fibra em detergente neutro (FDN) (Rogers et al., 2002), incluindo também uma proporção relativamente elevada de fibra em detergente ácido (FDA) e lignina. As frações fibrosas, como também a lignina, tendem a se correlacionar negativamente com a digestibilidade da matéria seca (MS) e da FDN (Moore et al., 1990; Torrent et al., 1994). Contudo, segundo Hall \& Akinyode (2000), a casca possui boa palatabilidade, favorecendo o aumento do consumo pelos animais.

Atualmente, pesquisas sobre a inclusão da casca de algodão na dieta de bovinos ainda são escassas. Portanto, não há uma recomendação adequada para seu uso, tampouco dos possíveis efeitos sobre o desempenho dos animais.

Diante disso, realizou-se este trabalho objetivandose avaliar a casca de algodão como substituto parcial à silagem de capim-elefante na alimentação de novilhos de origem leiteira em confinamento. Avaliaram-se os efeitos dessa substituição sobre o consumo dos nutrientes, o desempenho em confinamento, as características e a composição física da carcaça e o rendimento dos cortes comerciais dos animais.

\section{Material e Métodos}

O experimento foi realizado no Departamento de Zootecnia da Universidade Federal de Viçosa, em Viçosa, MG. Foram utilizados 18 bovinos mestiços de origem leiteira, com predomínio de sangue Holandês, com peso vivo médio inicial de 230 kg e média de 14 meses de idade, confinados em baias individuais, providas de comedouro e bebedouro, com área total de $30 \mathrm{~m}^{2}$, sendo $8 \mathrm{~m}^{2}$ cobertos com telhas de amianto.

Inicialmente, os animais foram pesados, após jejum alimentar de 16 horas, vermifugados e receberam, durante duas semanas, a dieta de adaptação, composta por $60 \%$ de volumoso (silagem de capimelefante e casca de algodão na proporção 40:20, respectivamente). Decorrido esse período, dois novilhos foram abatidos, para servirem de referência para estudos posteriores. Os 16 animais restantes foram novamente pesados e distribuídos aleatoriamente em quatro tratamentos, que consistiram de níveis crescentes de casca de algodão $(0,10,20$ e $30 \%$ com base na MS total), em substituição à silagem de capimelefante), de modo que a dieta total foi constituída de $60 \%$ de volumoso e $40 \%$ de concentrado. As rações foram balanceadas de forma a conterem aproximadamente $13,0 \%$ de proteína bruta (PB). O delineamento experimental utilizado foi o inteiramente casualizado, com quatro tratamentos e quatro repetições.

As proporções dos ingredientes nas dietas experimentais encontram-se na Tabela 1 e a composição média da casca de algodão e das dietas, na Tabela 2.

As rações foram fornecidas às $7 \mathrm{~h}$, efetuando-se o ajuste diário para manter as sobras em 5 a 10\% do total fornecido. Diariamente, foram elaboradas amostras compostas dos alimentos e das sobras, por animal e por período de 28 dias. O período experimental teve duração total de 56 dias. As amostras foram présecas em estufa ventilada a $65^{\circ} \mathrm{C}$ e processadas em moinho com peneira de malha de $1 \mathrm{~mm}$, para posteriores análises laboratoriais.

Foram determinados os teores de matéria seca (MS), matéria orgânica (MO), nitrogênio total, extrato etéreo (EE), lignina e minerais, de acordo com 
Tabela 1 - Proporção dos ingredientes nas dietas experimentais, com base na matéria seca, para os diferentes tratamentos

Table 1 - Ingredient composition of experimental diets on dry matter basis

\begin{tabular}{|c|c|c|c|c|}
\hline \multirow[t]{2}{*}{$\begin{array}{l}\text { Ingrediente (\%) } \\
\text { Ingredient (\%) }\end{array}$} & \multicolumn{4}{|c|}{$\begin{array}{c}\text { Nível de casca de algodão (\%) } \\
\text { Cottonseed hulls level (\%) }\end{array}$} \\
\hline & 0 & 10 & 20 & 30 \\
\hline $\begin{array}{l}\text { Silagem decapim-elefante } \\
\text { Elephantgrass silage }\end{array}$ & 60,0 & 50,0 & 40,0 & 30,0 \\
\hline $\begin{array}{l}\text { Casca de algodão } \\
\text { Cottonseed hulls }\end{array}$ & - & 10,0 & 20,0 & 30,0 \\
\hline $\begin{array}{l}\text { Grão de sorgo moído } \\
\text { Ground sorghum grain }\end{array}$ & 32,49 & 32,65 & 32,76 & 32,87 \\
\hline $\begin{array}{l}\text { Farelo de soja } \\
\text { Soybean meal }\end{array}$ & 4,50 & 4,50 & 4,50 & 4,50 \\
\hline $\begin{array}{l}\text { Uréia } \\
\text { Urea }\end{array}$ & 1,95 & 1,80 & 1,70 & 1,60 \\
\hline $\begin{array}{l}\text { Sulfato de amônia } \\
\text { Ammonium sulfate }\end{array}$ & 0,19 & 0,18 & 0,17 & 0,16 \\
\hline $\begin{array}{l}\text { Sal } \\
\text { Salt }\end{array}$ & 0,25 & 0,25 & 0,25 & 0,25 \\
\hline $\begin{array}{l}\text { Fosfato bicálcico } \\
\text { Dicalcium phosphate }\end{array}$ & 0,10 & 0,10 & 0,10 & 0,10 \\
\hline $\begin{array}{l}\text { Calcário } \\
\text { Limestone }\end{array}$ & 0,50 & 0,50 & 0,50 & 0,50 \\
\hline $\begin{array}{l}\text { Premix mineral } \\
\text { Mineral premix }^{1}\end{array}$ & 0,02 & 0,02 & 0,02 & 0,02 \\
\hline
\end{tabular}

${ }^{1}$ Composição (composition): sulfato de cobalto (cobalt sulfate), 1,82\%; sulfato de cobre (copper sulfate), 22,69\%; iodato de potássio (potassium iodate), $0,45 \%$; selenito de sódio (sodium selenite), 0,09\%; sulfato de zinco (zinc sulfate), $74,95 \%$.

técnicas descritas por Silva \& Queiroz (2002); de nitrogênio insolúvel em detergente neutro (NIDN) e ácido (NIDA), conforme descrição de Van Soest et al. (1991); e dos compostos nitrogenados nãoprotéicos (NNP), de acordo com Licitra et al. (1996). Os teores de fibra em detergente neutro (FDN) e fibra em detergente ácido (FDA) foram determinados conforme metodologia descrita por Pell \& Schofield (1993), denominada Micro-FDN.

Os carboidratos totais (CHOt) foram obtidos por meio da equação:

$C H O t=100-(\% P B+\% E E+\%$ Cinzas $)$, segundo Sniffen et al. (1992)

Em razão da presença de uréia nas dietas, os carboidratos não-fibrosos (CNF) foram calculados como proposto por Hall (2000):

$C N F=100-[(\% P B-\% P B$ derivada da uréia +

$\%$ de uréia $)+\% F D N c p+\% E E+\%$ cinzas]

Os animais foram pesados no início do período experimental e, posteriormente, a cada 28 dias, sempre após jejum alimentar de 16 horas, para determinação do ganho médio diário de peso vivo (GMD). Ao final do experimento, todos os animais foram abatidos por meio de atordoamento mecânico (marreta) na região do osso frontal, com posterior sangria. Após o abate, o aparelho gastrintestinal de cada animal foi esvaziado e, juntamente com os outros órgãos, foi lavado, pesado e somado às demais partes do corpo (carcaça, cabeça, couro, cauda, patas e sangue), para determinação do peso de corpo vazio (PCVZ). A relação obtida entre o PCVZ e o peso vivo (PV) dos animaisreferência, abatidos no início do experimento, foi utilizada para estimativa do PCVZ inicial dos animais, estimando-se, então, o ganho médio diário de peso de corpo vazio (GMDPVZ).

A carcaça de cada animal foi dividida ao meio com o auxílio de uma serra elétrica e, logo após, foi pesada, para determinação do ganho de carcaça e de seu rendimento em relação ao peso vivo (RCPV) e ao peso de corpo vazio (RCPVZ). Em seguida, as carcaças foram resfriadas em câmara fria a $-5^{\circ} \mathrm{C}$, durante aproximadamente 18 horas. Decorrido esse tempo, as meia-carcaças foram retiradas da câmara fria e novamente pesadas. Na carcaça direita, foi medido o comprimento e determinado o rendimento dos cortes comerciais, separando-se os quartos dianteiro e traseiro entre a quinta e a sexta costelas. O dianteiro compreendeu o acém e a paleta completa e o traseiro, a ponta-de-agulha, o coxão e a alcatra completa. $\mathrm{Na}$ carcaça esquerda, foram medidas a área transversal do músculo Longissimus dorsi (área de olho de lombo), à altura da 12a costela, e a espessura da gordura subcutânea. Também foi removido um corte da seção entre a 9a e 11 $\underline{\text { a }}$ costelas, para dissecação e predição das proporções de músculos, ossos e tecido adiposo na carcaça, segundo equações preconizadas por Hankins \& Howe (1946):

Proporção de músculo: $\mathrm{Y}=16,08+0,80 \mathrm{X}$

Proporção de tecido adiposo: $\mathrm{Y}=3,54+0,80 \mathrm{X}$

Proporção de ossos: $\mathrm{Y}=5,52+0,57 \mathrm{X}$

em que: $\mathrm{X}=$ porcentagem dos componentes no corte das costelas.

Os resultados foram interpretados estatisticamente por meio de análises de variância e regressão, utilizando-se o Sistema de Análises Estatísticas e Genéticas - SAEG (UFV, 1998). Os modelos foram testados com base na significância dos coeficientes de regressão, utilizando-se o teste $\mathrm{F}$ a $10 \%$ de probabilidade e o coeficiente de determinação $\left(\mathrm{r}^{2}\right)$. Previamente à 
Tabela 2 - Teores percentuais de matéria seca (MS), matéria orgânica (MO), proteína bruta (PB), nitrogênio não-protéico (NNP), nitrogênio insolúvel em detergente neutro (NIDN), nitrogênio insolúvel em detergente ácido (NIDA), extrato etéreo (EE), carboidratos totais (CHOT), fibra em detergente neutro (FDN), fibra em detergente neutro corrigida para cinzas e proteína (FDNcp), carboidratos não-fibrosos (CNF), lignina, cálcio (Ca), fósforo $(\mathrm{P})$, sódio $(\mathrm{Na})$, potássio $(\mathrm{K})$ e magnésio $(\mathrm{Mg})$ da casca de algodão e das dietas experimentais, com base na matéria seca

Table 2 - Contents of dry matter (DM), organic matter (OM), crude protein (CP), nonprotein nitrogen (NPN), neutral detergent insoluble nitrogen (NDIN), acid detergent insoluble nitrogen (ADIN), ether extract (EE), total carbohydrates (TCHO), neutral detergent fiber (NDF), neutral detergent fiber corrected for ash and protein (NDFap), non fiber carbohydrates (NFC), lignin, calcium (Ca), phosphorus (P), sodium ( $\mathrm{Na}$ ), potassium (K), and magnesium ( $\mathrm{Mg}$ ) of cottonseed hulls and experimental diets on dry matter basis

\begin{tabular}{|c|c|c|c|c|c|}
\hline \multirow[t]{2}{*}{$\begin{array}{l}\text { Variável } \\
\text { Variable }\end{array}$} & \multicolumn{4}{|c|}{$\begin{array}{c}\text { Nível de casca de algodão (\%) } \\
\text { Cottonseed hulls level (\%) }\end{array}$} & \multirow[t]{2}{*}{$\begin{array}{l}\text { Casca de algodãc } \\
\text { Cottonseed hulls }\end{array}$} \\
\hline & 0 & 10 & 20 & 30 & \\
\hline $\mathrm{MS}(D M)$ & 51,72 & 57,88 & 64,04 & 70,20 & 88,09 \\
\hline $\mathrm{MO}(\mathrm{OM})$ & 90,68 & 91,48 & 92,22 & 92,97 & 97,29 \\
\hline $\mathrm{PB}(C P)$ & 13,35 & 13,30 & 13,41 & 13,52 & 8,19 \\
\hline $\operatorname{NNP}(N P N)^{1}$ & 56,34 & 51,88 & 47,87 & 43,92 & $9,0^{2}$ \\
\hline $\operatorname{NIDN}(N D I N)^{2}$ & 19,22 & 20,06 & 20,90 & 21,74 & 29,73 \\
\hline NIDA $(A D I N)^{2}$ & 6,73 & 6,11 & 5,84 & 5,57 & 6,07 \\
\hline $\mathrm{EE}$ & 2,38 & 2,76 & 3,13 & 3,50 & 5,31 \\
\hline CHOT (ТСHO) & 81,46 & 81,49 & 81,47 & 81,45 & 83,79 \\
\hline FDN (NDF) & 49,09 & 49,46 & 49,84 & 50,21 & 78,01 \\
\hline FDNcp (NDFap) & 47,39 & 47,74 & 48,08 & 48,43 & 75,41 \\
\hline CNF (NFC) & 34,07 & 33,75 & 33,39 & 33,02 & 8,38 \\
\hline Lignina (Lignin) & 7,02 & 7,12 & 7,22 & 7,32 & 11,54 \\
\hline $\mathrm{Ca}$ & 0,81 & 0,70 & 0,64 & 0,58 & 0,21 \\
\hline $\mathrm{P}$ & 0,35 & 0,33 & 0,32 & 0,31 & 0,24 \\
\hline $\mathrm{Na}$ & 0,08 & 0,07 & 0,07 & 0,06 & 0,04 \\
\hline K & 2,46 & 2,20 & 1,99 & 1,78 & 1,35 \\
\hline $\mathrm{Mg}$ & 0,37 & 0,33 & 0,32 & 0,32 & 0,30 \\
\hline
\end{tabular}

$1 \%$ de PB (\% of CP).

$2 \%$ de $\mathrm{N}$ total (\% of total $\mathrm{N}$ ).

análise de variância, os dados foram avaliados quanto às pressuposições de normalidade e homocedasticidade por meio dos testes de Lilliefors e Cochran, respectivamente.

\section{Resultados e Discussão}

Constam na Tabela 3 os consumos médios de MS, MO, PB, EE, FDN, CNF e NDT, com respectivas equações de regressão e probabilidades (Valor $P$ ), além dos coeficientes de variação e determinação, pelos animais nos diferentes tratamentos.

O desempenho animal é determinado por vários fatores, entre os quais o mais importante é o consumo de MS (Illius \& Jessop, 1996), visto que determina o nível de ingestão de nutrientes (Van Soest, 1994). O uso de alimentos ricos em fibra e pouco digestíveis geralmente reduz o consumo de MS, como consequência da quantidade de material indigestível que ocupa espaço dentro do rúmen, limitando sua capacidade física de distenção.

Entretanto, verificou-se que a inclusão da casca de algodão em níveis crescentes na dieta aumentou linearmente $(\mathrm{P}<0,10)$ o consumo de MS, expresso em relação ao peso vivo (PV). Vale ressaltar que, no início do período de adaptação, os animais selecionavam a casca dos demais ingredientes da dieta. Por isso, durante boa parte do experimento, as sobras foram constituídas quase que totalmente de casca de algodão. Porém, à medida que os sacos que armazenavam a casca eram manipulados, os pellets se quebravam, facilitando sua mistura aos demais ingredientes e tornando mais difícil a seleção pelos animais.

Resultados semelhantes foram encontrados por Moore et al. (1990), que, ao avaliarem a influência do tipo de volumoso (feno de alfafa, palha de trigo e 
casca de algodão) sobre o desempenho de novilhos alimentados com dietas ricas em concentrado, verificaram que aqueles que receberam casca de algodão aumentaram o consumo de MS em 17\% quando comparados aos animais do tratamento controle. Bartle et al. (1994) e Gu \& Moss (1996), ao incluírem na dieta de bovinos os mesmos níveis de casca deste trabalho, observaram que o consumo de MS também aumentou linearmente. Da mesma forma, Oltjen et al. (1977), avaliando o desempenho de novilhos alimentados com diferentes subprodutos (palha de aveia picada, planta inteira de milho e casca de algodão), verificaram maior consumo de MS para os animais que receberam a casca $(3,1 \%$ do $\mathrm{PV})$.

$\mathrm{O}$ consumo de FDN, expresso como \% do PV, aumentou linearmente com os níveis de inclusão da casca nas dietas, registrando-se valor de 1,63\% do PV para o nível de $30 \%$ de casca de algodão. O mesmo ocorreu para o consumo de EE, o que era esperado, uma vez que a casca de algodão possui teor relativamente elevado desse nutriente.

As alterações no consumo de MS que ocorrem quando a casca de algodão é fornecida aos animais podem elevar o consumo de FDN em níveis acima dos usuais (Hall \& Akinyode, 2000). Mertens (1994) sugeriu que o consumo de FDN deveria ser próximo a 1,2\% do PV por dia. Essa recomendação foi estimada de forma a permitir suplementação adequada de concentrado e prevenir a limitação do consumo pelo enchimento do rúmen. Quando a FDN da dieta provém, em sua maioria, da forragem, tem-se observado (Hall \& Akinyode, 2000) consumo próximo ao valor sugerido por Mertens (1994). Entretanto, Morales et al. (1989) ao fornecerem casca de algodão na dieta, verificaram que o consumo de FDN atingiu o valor de 1,5\% do PV dos animais. A inclusão da casca de algodão não afetou $(\mathrm{P}>0,10)$ os consumos de $\mathrm{MO}, \mathrm{PB}, \mathrm{CNF}$ e NDT, apresentando médias de 7,64; 1,15; 2,93 e 5,36 kg/dia, respectivamente.

As médias, as probabilidades (Valor $P$ ) e os coeficientes de variação (CV) obtidos para os pesos vivos iniciais (PVI) e final (PVF), os ganhos médios diários de peso vivo (GMD) e de peso de corpo vazio (GMDPVZ), os ganhos de carcaça (GCAR), a conversão alimentar (CA) e a relação PCVZ/PV, para os diferentes tratamentos, são apresentados na Tabela 4. Verificou-se que não houve influência $(P>0,10)$ dos níveis de casca de algodão sobre as variáveis estuda-

Tabela 3 - Médias, equações de regressão, probabilidades (Valor $P$ ), coeficientes de variação (CV) e determinação ( ${ }^{2}$ ) obtidos para os consumos de matéria seca (MS), matéria orgânica (MO), proteína bruta (PB), extrato etéreo (EE), fibra em detergente neutro (FDN), carboidratos não-fibrosos (CNF) e nutrientes digestíveis totais (NDT) nos diferentes tratamentos

Table 3 - Means, regression equations, probabilities ( $P$ value), coefficients of variation (CV) and determination $\left(r^{2}\right)$, for intakes of dry matter $(D M)$, organic matter $(O M)$, crude protein $(C P)$, ether extract (EE), neutral detergent fiber (NDF), nonfiber carbohydrates (NFC), and total digestible nutrients (TDN) for the different treatments

\begin{tabular}{|c|c|c|c|c|c|c|}
\hline \multirow[t]{2}{*}{$\begin{array}{l}\text { Variável } \\
\text { Variable }\end{array}$} & \multicolumn{4}{|c|}{$\begin{array}{c}\text { Nível de casca de algodão (\%) } \\
\text { Cottonseed hulls level (\%) }\end{array}$} & \multirow[t]{2}{*}{$\begin{array}{l}\text { Valor } P \\
P \text { value }\end{array}$} & \multirow[t]{2}{*}{ CV $(\%)$} \\
\hline & 0 & 10 & 20 & 30 & & \\
\hline \multicolumn{7}{|c|}{$\begin{array}{l}\text { Consumo (kg/dia) } \\
\text { Intake (kg/day) }\end{array}$} \\
\hline MS (DM) & 7,80 & 7,98 & 8,77 & 8,15 & 0,57 & 19,71 \\
\hline $\mathrm{MO}(\mathrm{OM})$ & 7,05 & 7,29 & 8,09 & 8,14 & 0,44 & 19,65 \\
\hline $\mathrm{PB}(C P)$ & 1,09 & 1,11 & 1,22 & 1,18 & 0,53 & 18,78 \\
\hline $\mathrm{EE}^{1}(E E)$ & 0,20 & 0,23 & 0,28 & 0,30 & 0,002 & 16,52 \\
\hline FDN (NDF) & 3,64 & 3,77 & 4,21 & 4,22 & 0,42 & 19,95 \\
\hline CNF (NFC) & 2,81 & 2,87 & 3,04 & 2,98 & 0,56 & 19,18 \\
\hline $\operatorname{NDT}(T D N)$ & 5,40 & 5,16 & 5,54 & 5,33 & 0,73 & 18,61 \\
\hline \multicolumn{7}{|c|}{$\begin{array}{c}\text { Consumo }(\% \mathrm{PV}) \\
\text { Intake }(\% \mathrm{BW})\end{array}$} \\
\hline $\mathrm{MS}^{2}(D M)$ & 2,73 & 2,81 & 3,03 & 3,38 & 0,003 & 8,39 \\
\hline $\mathrm{FDN}^{3}(N D F)$ & 1,27 & 1,33 & 1,45 & 1,63 & 0,001 & 8,47 \\
\hline
\end{tabular}

$1 \hat{\mathrm{Y}}=0,1934+0,0042 * \mathrm{CA} ; \mathrm{r}^{2}=0,98$

$2 \hat{Y}=2,6666+0,020{ }^{\star} C A ; r^{2}=0,92$

$3 \hat{\mathrm{Y}}=1,2425+0,0117^{*} \mathrm{CA} ; \mathrm{r}^{2}=0,94$ 
das, com exceção da relação PCVZ/PV, que apresentou comportamento linear crescente $(P<0,10)$. Apesar do consumo de MS ter aumentado linearmente com a inclusão da casca na dieta, o GMD não teve a mesma tendência, apresentando média de 1,30 kg/ animal/dia.

Resultados semelhantes foram observados por Hale et al. (1969). Entretanto, Bartle et al. (1994), pesquisando os mesmos níveis de casca utilizados neste trabalho, verificaram que os novilhos que receberam casca apresentaram maior consumo, porém tenderam a ganhar menos peso e tiveram CA pior que aqueles alimentados com feno de alfafa. Os autores atribuíram a ausência de resposta no ganho de peso com o aumento do consumo à baixa digestibilidade $\mathrm{e}$ ao baixo valor energético da casca de algodão.

Os efeitos da casca sobre a eficiência e o desempenho animal têm sido variados. Murdock \& Wallenius (1980) relataram maiores consumos e ganhos de peso em bezerros holandeses alimentados com casca de algodão que com outras fontes de fibra na dieta. Thomas et al. (1984) observaram aumento no ganho médio diário e na eficiência alimentar em novilhos recebendo dieta composta por $60 \%$ de milho quebrado e $30 \%$ de casca de algodão, adicionada de $0,7 \%$ de uréia na MS total. De acordo com Hall \& Akinyode (2000), os dados encontrados na literatura sugerem que níveis elevados de casca na dieta (30\% na MS total) têm proporcionado consumos elevados sem, no entanto, aumentar a produtividade animal.

Na Tabela 5 encontram-se as médias, probabilidades (Valor $P$ ) e os coeficientes de variação obtidos para características de carcaça e rendimento dos cortes comerciais. As análises de variância não evidenciaram influência $(\mathrm{P}>0,10)$ dos níveis de casca de algodão sobre as variáveis estudadas. Os rendimentos de carcaça quente e fria, expressos em relação ao PV, apresentaram valores médios de 48,93 e 47,69\%, respectivamente. Para bovinos mestiços holandeses, esses valores estão de acordo com os dados da literatura (Souza et al., 2002; Moraes, 2003), quando esses animais são abatidos entre 250 e 350 kg de peso vivo.

A gordura subcutânea é uma fração importante, pois serve como proteção contra a desidratação durante o resfriamento das carcaças (Moletta \& Restle, 1996). Por muitos anos, a espessura de gordura tem sido utilizada como medida de acabamento externo e medida indireta de musculosidade da carcaça, em função da correlação negativa entre ambas. Uma cobertura de gordura subcutânea satisfatória para boa preservação deve ser, no mínimo, de 2 a $3 \mathrm{~mm}$ (Luchiari Filho, 2000). Os animais utilizados neste trabalho não apresentaram cobertura de gordura mínima desejada (1,08 mm, em média). Segundo Marquat (1964), a porcentagem de gordura na carcaça de novilhos mestiços de raças leiteiras aumenta após os animais atingirem, aproximadamente, $454 \mathrm{~kg}$ de PV. Neste estudo, os animais foram abatidos com $329 \mathrm{~kg}$ de PV médio final, portanto, insuficiente para que apresentassem acabamento adequado.

Não foi verificado efeito dos níveis de casca de algodão da dieta $(\mathrm{P}>0,10)$ sobre os cortes comerciais. O grau de rendimento dos cortes cárneos desossados e aparados do excesso de gordura é uma estimativa da

Tabela 4 - Médias, probabilidades (Valor $P$ ) e coeficientes de variação (CV), obtidos para os pesos vivos inicial (PVI) e final (PVF), ganhos médios diários de peso vivo (GMD) e de peso de corpo vazio (GMDPVZ), ganhos de carcaça (GCAR), conversão alimentar (CA) e relação PCVZ/PV nos diferentes tratamentos

Table 4 - Means, probabilities (P value) and coefficients of variation (CV) for the initial body weight (IBW) and final body weight (FBW), average daily gains of body weight (ADG) and of empty body weight (ADGEBW), carcass gains (CARG), feed:gain ratio and the EBW/BW ratio in response to different treatments

\begin{tabular}{|c|c|c|c|c|c|c|}
\hline \multirow[t]{2}{*}{$\begin{array}{l}\text { Variável } \\
\text { Variable }\end{array}$} & \multicolumn{4}{|c|}{$\begin{array}{l}\text { Nível de casca de algodão (\%) } \\
\text { Cottonseed hulls level (\%) }\end{array}$} & \multirow[t]{2}{*}{$\begin{array}{l}\text { Valor } P \\
P \text { value }\end{array}$} & \multirow[t]{2}{*}{$\mathrm{CV}(\%)$} \\
\hline & 0 & 10 & 20 & 30 & & \\
\hline PVF, $\mathrm{kg}(F B W, k g)$ & 331,0 & 330,5 & 329,0 & 325,4 & 0,92 & 24,71 \\
\hline GMD, kg/dia (ADG, kg/day) & 1,27 & 1,38 & 1,21 & 1,34 & 0,97 & 11,44 \\
\hline GMDPVZ, kg/dia (ADGEBW, kg/day) & 0,96 & 1,12 & 1,17 & 1,06 & 0,49 & 20,42 \\
\hline PCVZ/PV (EBW/BW) & 79,36 & 80,23 & 83,74 & 82,73 & 0,01 & 2,53 \\
\hline
\end{tabular}


Tabela 5 - Médias, equações de regressão, probabilidades (Valor $P$ ), coeficientes de variação (CV) e determinação ( $\left.r^{2}\right)$, obtidos para os rendimentos de carcaça quente em relação ao peso vivo (RCPV) e ao peso de corpo vazio (RCPCVZ), rendimento de carcaça fria (RCFPV), comprimento de carcaça (CCAR), área de olho de lombo (AOL), espessura de gordura subcutânea (EGS) e rendimentos dos cortes comerciais nos diferentes tratamentos

Table 5 - Means, regression equations, probabilities ( $P$ value), coefficients of variation (CV) and determination ( $\left.r^{2}\right)$ for hot carcass dressing percentage in relation to body weight (HCPBW) and to empty body weight (HCPEBW), cold carcass dressing percentage (CCPBW), carcass length (CL), rib eye area (REA), fat thickness (FT) and trade cuts for the different treatments

\begin{tabular}{|c|c|c|c|c|c|c|}
\hline \multirow[t]{2}{*}{$\begin{array}{l}\text { Variável } \\
\text { Variable }\end{array}$} & \multicolumn{4}{|c|}{$\begin{array}{l}\text { Nível de casca de algodão (\%) } \\
\text { Cottonseed hulls level (\%) }\end{array}$} & \multirow[t]{2}{*}{$\begin{array}{l}\text { Valor } P \\
P \text { value }\end{array}$} & \multirow[t]{2}{*}{ CV $(\%)$} \\
\hline & 0 & 10 & 20 & 30 & & \\
\hline \multicolumn{7}{|c|}{$\begin{array}{l}\text { Características de carcaça } \\
\text { Carcass characteristics }\end{array}$} \\
\hline RCQPV, \%(HCPLW) & 48,30 & 47,86 & 50,74 & 48,82 & 0,37 & 4,55 \\
\hline RCQPCVZ, \% (HCPEBW) & 60,85 & 59,62 & 60,59 & 59,07 & 0,33 & 2,90 \\
\hline RCFPV, \% (CCPLW) & 47,16 & 46,72 & 49,48 & 47,38 & 0,49 & 5,0 \\
\hline CCAR, cm (CL) & 113,0 & 112,0 & 109,0 & 110,0 & 0,46 & 7,15 \\
\hline $\mathrm{AOL}, \mathrm{cm}^{2}(R E A)$ & 64,33 & 53,35 & 59,10 & 52,12 & 0,31 & 21,84 \\
\hline $\mathrm{AOL}, \mathrm{cm}^{2} / \mathrm{kg}$ de carcaça & 0,41 & 0,36 & 0,37 & 0,31 & 0,17 & 22,01 \\
\hline$R E A\left(\mathrm{~cm}^{2} / \mathrm{kg}\right.$ of carcass $)$ & & & & & & \\
\hline $\mathrm{EGS}, \mathrm{mm}^{1}(\mathrm{FT})$ & 0,65 & 1,15 & 1,30 & 1,23 & 0,06 & 36,91 \\
\hline \multicolumn{7}{|c|}{$\begin{array}{l}\text { Rendimento dos cortes comerciais (\%) } \\
\text { Trade cuts }\end{array}$} \\
\hline Acém (Beef chuck) & 21,41 & 20,88 & 21,66 & 20,99 & 0,87 & 6,47 \\
\hline Paleta (Shoulder clod) & 17,40 & 17,41 & 17,26 & 18,08 & 0,41 & 5,93 \\
\hline Dianteiro (Fore quarter) & 38,81 & 38,30 & 38,92 & 39,07 & 0,44 & 2,04 \\
\hline Alcatra (Top sirloin butt) & 19,04 & 18,71 & 18,82 & 18,65 & 0,67 & 6,17 \\
\hline Coxão (Beefround) & 29,54 & 30,10 & 29,11 & 29,90 & 0,98 & 4,81 \\
\hline Traseiro especial (Hind quarter) & 48,58 & 48,81 & 47,93 & 48,55 & 0,64 & 1,90 \\
\hline Ponta de agulha (Plate) & 12,61 & 12,90 & 13,16 & 12,38 & 0,80 & 5,48 \\
\hline
\end{tabular}

${ }^{1} \hat{Y}=0,79+0,0202^{*} \mathrm{CA} ; r^{2}=0,90$

quantidade de carne comercializável ou da porção comestível de uma carcaça. É desejável que uma carcaça apresente 45 a 50\% de traseiro especial, 38 a $43 \%$ de dianteiro com cinco costelas e 12 a $16 \%$ de ponta-de-agulha (Luchiari Filho, 2000). Os resultados obtidos estão de acordo com esses valores. Verifica-se escassez de dados na literatura com relação ao estudo do rendimento dos cortes comerciais, em bovinos mestiços leiteiros, particularmente quando se utiliza casca de algodão na dieta.

Os resultados referentes à composição física da carcaça dos novilhos são apresentados na Tabela 6 . Não foi verificada influência $(\mathrm{P}>0,10)$ dos tratamentos sobre as porcentagens dos tecidos muscular, adiposo e ósseo na carcaça, obtendo-se médias de 61,44; 20,62 e 18,03\%, respectivamente. Esses valores corroboram os resultados encontrados por Rocha et al. (1999), Leme et al. (2000) e Rodrigues Filho et al. (2003), que também mensuraram a composição física da carcaça de novilhos machos oriundos de rebanhos leiteiros.
Não foram encontrados trabalhos que apresentassem informações sobre os efeitos de níveis de volumosos alternativos em substituição a silagens de forrageiras tropicais sobre a composição da carcaça de bovinos. Além disso, não há relatos envolvendo possíveis efeitos da inclusão da casca de algodão na dieta de bovinos sobre a composição da carcaça.

\section{Conclusões}

A substituição parcial da silagem de capimelefante pela casca de algodão na dieta não afetou a composição física e as características de carcaça dos animais e o rendimento dos cortes comerciais.

O nível máximo de casca de algodão utilizado no experimento (30\% na MS total) resultou em desempenho adequado de novilhos mestiços de origem leiteira em confinamento. 
Tabela 6 - Médias, probabilidades (Valor $P$ ) e coeficientes de variação (CV), obtidos para as porcentagens dos tecidos muscular, adiposo e ósseo na carcaça nos diferentes tratamentos

Table 6 - Means, probabilities ( $P$ value) and coefficients of variation $(\mathrm{CV})$ for percentages of muscle, fat and bone in the carcass for the different treatments

\begin{tabular}{|c|c|c|c|c|c|c|}
\hline \multirow[t]{2}{*}{$\begin{array}{l}\text { Variável } \\
\text { Variable }\end{array}$} & \multicolumn{4}{|c|}{$\begin{array}{c}\text { Nível de casca de algodão (\%) } \\
\text { Cottonseed hulls level (\%) }\end{array}$} & \multirow[t]{2}{*}{$\begin{array}{l}\text { Valor } P \\
P \text { value }\end{array}$} & \multirow[t]{2}{*}{ CV $(\%)$} \\
\hline & 0 & 10 & 20 & 30 & & \\
\hline $\begin{array}{l}\text { Peso de carcaça fria, } \mathrm{kg} \\
\text { Cold carcass weight }\end{array}$ & 157,6 & 156,2 & 163,7 & 158,3 & 0,92 & 29,36 \\
\hline $\begin{array}{l}\text { Músculo, \% } \\
\text { Muscle }\end{array}$ & 62,04 & 61,21 & 61,41 & 61,11 & 0,74 & 6,01 \\
\hline $\begin{array}{l}\text { Gordura, \% } \\
\text { Fat }\end{array}$ & 19,88 & 20,07 & 21,75 & 20,78 & 0,53 & 15,75 \\
\hline $\begin{array}{l}\text { Osso, \% } \\
\text { Bone }\end{array}$ & 18,13 & 18,59 & 17,25 & 18,15 & 0,76 & 10,91 \\
\hline
\end{tabular}

\section{Literatura Citada}

BARTLE, S.J.; PRESTON, R.L.; MILLER, M.F. Dietary energy source and density: effects of roughage source, roughage equivalent, tallow level and steer type on feedlot performance and carcass characteristics. Journal of Animal Science, v.72, n.8, p.1943-1953, 1994.

CONAB - Companhia Nacional de Abastecimento, www.conab.gov.br (20/09/2005).

GU, S.C.; MOSS, B.R. Lactation performance of cows fed low and high rumen undegradable protein diets with varying levels of cottonseed hulls and protein. Journal of Dairy Science, v.79, p.152, 1996 (Supplement 1).

HALE, W.H.; LAMBETH, C.; THEURER, B. et al. Digestibility and utilization of cottonseed hulls by cattle. Journal of Animal Science, v.29, n.5, p.773-776, 1969.

HALL, M.B. Calculation of non-structural carbohydrate content of feeds that contain non-protein nitrogen. University of Florida, 2000. A25-A34 (Bulletin 339).

HALL, M.B.; AKINYODE, A. Cottonseed hulls: working with a novel fiber source. In: Annual Florida Ruminant Nutrition Symposium, 11., 2000, Gainesville. Proceedings... Gainesville: 2000. p.179-186.

HANKINS, O.G.; HOWE, P.E. Estimation of the composition of beef carcasses and cuts. [T.B.]: United Sates Department of Agriculture, 1946. p.1-19 (Technical Bulletin, 926).

HSU, J.T.; FAULKNER, D.B.; GARLEB, K.A. et al. Evaluation of corn fiber, cottonseed hulls, oat hulls and soybean hulls as roughage sources for ruminants. Journal of Animal Science, v.65, n.1, p.244-255, 1987.

ILLIUS, A.M.; JESSOP, N.S. Metabolic constraints on voluntary intake in ruminants. Journal of Animal Science, v.74, n.12, p.3052-3062, 1996.

LEME, P.R.; BOIN. C.; MARGARIDO, R.C.C. et al. Desempenho em confinamento e características de carcaça de bovinos machos de diferentes cruzamentos abatidos em três faixas de peso. Revista Brasileira de Zootecnia, v.29, n.6, p.23472353, 2000 (Suplemento 2).

LICITRA, G.; HERNANDEZ, T.M.; VAN SOEST, P.J. Standardization of procedures for nitrogen fractionation of ruminant feeds. Animal Feed Science and Technology, v.57, p.347-358, 1996.
LUCHIARI FILHO, A. Pecuária da carne bovina. 1.ed. São Paulo: R.Vieira Gráfica \& Editora Ltda, 2000. 134p.

MARQUAT, W.R. Dairy beef in packing industry. Journal of Animal Science, v.47, n.10, p.1145-1149, 1964.

MERTENS, D.R. Regulation of forage intake. In: FAHEY Jr., G.C. (Ed.) Forage quality, evaluation and utilization. In: NATIONAL CONFERENCE ON FORAGE QUALITY, EVALUATION AND UTILIZATION. American Society of Agronomy, 1994. p.450-493.

MOLLETA, J.L.; RESTLE, J. Características de carcaças de novilhos de diferentes grupos genéticos terminados em confinamento. Revista Brasileira de Zootecnia, v.25, n.5, p.876-888, 1996.

MOORE, J.A.; POORE, M.H.; SWINGLE, R.S. Influence of roughage source on kinetics of digestion and passage, and on calculated extents of ruminal digestion in beef steers fed $65 \%$ concentrate diets. Journal of Animal Science, v.68, n.10, p.3412-3420, 1990.

MORAES, E.H.B.K. Suplementos múltiplos para recria e terminação de novilhos mestiços em pastejo durante os períodos de seca e transição seca-águas. Viçosa, MG: Universidade Federal de Viçosa, 2003. 70p. Dissertação (Mestrado em Zootecnia) - Universidade Federal de Viçosa, 2003.

MORALES, J.L.; Van HORN, H.H.; MOORE, J.E. Dietary interaction of cane molasses with source of roughage: intake and lactation effects. Journal of Dairy Science, v.72, n.9, p.2331-2338, 1989.

MURDOCK, F.R.; WALLENIUS, R.W. Fiber sources for complete calf starter rations. Journal of Animal Science, v.63, n.11, p.1869-1873, 1980.

OLTJEN, R.R.; DINIUS, D.A.; GOERING, H.K. Performance of steers fed crop residues supplemented with nonprotein nitrogen, minerals, protein and monensin. Journal of Animal Science, v.45, n.6, p.1442-1452, 1977.

PELL, A.N.; SCHOFIELD, P. Computerized monitoring of gas production to measure forage digestion in vitro. Journal of Dairy Science, v.76, n.4, p.1063-1073, 1993.

ROCHA, E.O.; FONTES, C.A.A.; PAULINO, M.F. et al. Ganho de peso, eficiência alimentar e características da carcaça de novilhos de origem leiteira. Revista Brasileira de Zootecnia, v.28, n.1, p.148-158, 1999. 
RODRIGUES FILHO, M.; MANCIO, A.B.; LANA, R.P. et al. Desempenho e característica de carcaça de novilhos de origem leiteira, alimentados com diferentes níveis de concentrado e de cama de frango. Revista Brasileira de Zootecnia, v.32, n.3, p.672-682, 2003.

ROGERS, G.M.; POORE, M.H.; PASCHAL, J.C. Feeding cotton products to cattle. The Veterinary Clinics Food Animal Practice, v.18, p.267-294, 2002.

SILVA, D.J.; QUEIROZ, A.C. Análise de alimentos (métodos químicos e biológicos). 3.ed. Viçosa, MG: Universidade Federal de Viçosa, 2002. 235p.

SNIFFEN, C.J.; O’CONNOR, J.D.; Van SOEST, P.J. et al. A net carbohydrate and protein system for evaluating cattle diets: II. Carbohydrate and protein availability. Journal of Animal Science, v.70, n.11, p.3562-3577, 1992.

SOUZA, V.G.; PEREIRA, O.G.; VALADARES FILHO, S.C. et al. Consumo e desempenho de bovinos de corte recebendo dietas com diferentes níveis de uréia. In: REUNIÃO ANUAL DA SOCIEDADE BRASILEIRA DE ZOOTECNIA, 39., 2002, Recife. Anais... Recife: Sociedade Brasileira de Zootecnia, 2002. Nutrição de Ruminantes. (CD-ROM)

THOMAS, E.E.; MASON, C.R.; SCHMIDT, S.P. Relation of performance and certain physiological responses to the metabolizable protein and urea content of cattle diets. Journal of Animal Science, v.58, n.5, p.1285-1291, 1984.

TORRENT, J.; JOHNSON, D.E.; KUJAWA, M.A. Co-product fiber digestibility: kinetic and in vivo assessment. Journal of Animal Science, v.72, n.3, p.790-795, 1994.
UNIVERSIDADE FEDERAL DE VIÇOSA - UFV. SAEG Sistema de Análises Estatísticas e Genéticas. Versão 8.0. Viçosa, MG: Universidade Federal de Viçosa, 1998. 150p. (Manual do usuário).

VALADARES FILHO, S.C.; PAULINO, P.V.R.; MAGALHÃES, K.A. et al. Modelos nutricionais alternativos para otimização de renda na produção de bovinos de corte. In: SIMPÓSIO DE PRODUÇÃO DE GADO DE CORTE, 3., 2002, Viçosa, MG. Anais... Viçosa, MG: Universidade Federal de Viçosa, 2002. p.197-254.

Van SOEST, P.J.; ROBERTSON, J.B.; LEWIS, B.A. Methods for dietary fiber, neutral detergent fiber, and nonstarch polyssacarides in relation to animal nutrition. Journal of Animal Science, v.74, n.10, p.3583-3597, 1991.

Van SOEST, P.J. Nutritional ecology of the ruminant. 2.ed. London: Constock Publishing Associates, 1994. 476p.

VERNLUND, S.D.; HARRIS, B.; Van HORN, H.H. et al. Effects of masonex and forms of cottonseed hulls on dairy cows. Journal of Dairy Science, v.63, n.12, p.2037-2043, 1980. 